Tạp chí Khoa học và Công nghệ biển T10 (2010). Số 3. Tr 69 - 75

\title{
ẢNH HỬ̛̉NG CỦA CÁC LOẠI THỨC ĂN LÊN TỶ LẸ SỐNG VÀ TỐC Độ TĂNG TRƯ ỞNG CỦA CÁ KHOANG CỔ NEMO CON (AMPHIPRION OCELLARIS CUVIER, 1830)
}

\author{
NGUYẼ̃N TH!̣ THANH THỦY, HÀ LÊ TH!̣ LỘC
}

Viện Hải dương học

\begin{abstract}
Tóm tắt: Cá khoang cổ nemo 15 ngày tuổi được nuôi trong hệ thống nước hở gồm các bể kính có thể tích 15lít, mật độ 2 con/lit, với 4 loại thức ăn khác nhau: lô 1: ấu trùng (Nauplius) của Artemia (mật độ $5-7 \mathrm{con} / \mathrm{ml}$ ); lô 2: thịt tôm tươ xay nhỏ; lô 3: thức ăn tổng hợp (VANNA); lô 4: Copepoda (mật độ $5-7 \mathrm{con} / \mathrm{ml}$ ). Các lô thí nghiệm được kiểm tra tỷ lệ sống và quan sát tình trạng sức khỏe của cá hàng ngày. Định kỳ cân, đo cá 10 ngày/làn, xác định tăng truởng chiều dài $(L, m m)$, khối luợng $(W, g)$ và tốc độ sinh truởng đặc trung ngày về chiều dài toàn thân $\left(S G R_{L}\right)$ của các lô cá thí nghiệm. Kết quả cho thấy tăng truởng chiều dài và khối luợng của cá khoang cổ nemo 60 ngày tuổi ăn Copepoda $(21,8 \mathrm{~mm}$ và $0,204 \mathrm{~g})$ và thức ăn tổng hợp $(21,5 \mathrm{~mm}$ và $0,19 \mathrm{~g})$ cao hơn đáng kể so với cá ăn Artemia $(20,3 \mathrm{~mm} ; 0,16 \mathrm{~g})$ và ăn tôm (17,2mm; 0,102 g). Tốc độ sinh truởng đặc trung trung bình ngày của lô cá ăn Copepoda (1\%/ngày) và thức ăn tổng hợp (0,98\%/ngày) cao hơn đáng kể so với cá ăn Artemia (0,87\%/ngày) và thịt tôm (0,53\%/ngày). Tỷ lệ sống của cá khoang cổ nemo 60 ngày tuổi dao động tù 74 - 88\%, đạt cao nhất ở lô cá ăn Artemia (88\%), tiếp theo là cá ăn thức ăn tổng hợp (84\%), Copepoda (80\%) và thấp nhất ở lô cá ăn thịt tôm (74\%).
\end{abstract}

\section{MỞ ĐÀ̀U}

Cá Khoang cổ nemo (Amphiprion ocellaris) là một trong những loài cá cảnh được ưa chuộng nhất trong giống cá khoang cổ do chúng có dáng vẻ mềm mại, màu sắc sặc sỡ và dễ thích nghi trong điều kiện nuôi giữ. Trước đây cá khoang cổ nemo chưa được phát hiện ở vùng biển Việt Nam, trên thị trường cá cảnh trong nước, đối tượng này chủ yếu được nhập từ các nước trong khu vực, với giá dao động từ 150 - 200 ngàn đồng/con và thường cao hơn gấp 10 lần so với các loài cá khoang cổ khác. Thời gian gần đây, cá khoang cổ nemo đã được phát hiện ở khu vực quần đảo Trường Sa nhưng với số lượng không nhiều.

Trên cơ sở những kết quả nghiên cứu đã đạt được từ loài cá Khoang cổ đỏ (Hà Lê Thị Lộc, 2004; 2005; Hà Lê Thị Lộc, Nguyễn Thị Thanh Thủy, 2009), cá khoang cổ nemo đã được thử nghiệm sinh sản thành công. Nghiên cứu ảnh hưởng của các loại thức ăn khác 
nhau lên tỷ lệ sống và tốc độ tăng trưởng của cá khoang cổ nemo là một nội dung nghiên cứu của đề tài cấp nhà Nước giai đoạn 2008 - 2010.

\section{PHƯƠNG PHÁP NGHIÊN CỨU}

Thí nghiệm được tiến hành từ tháng 6/2009 đến tháng 12/2009 tại khu thực nghiệm phòng Công nghệ nuôi trồng, Viện Hải dương học. Cá khoang cổ nemo (Amphiprion ocellaris) 15 ngày tuổi được chia ngẫu nhiên làm 4 lô thí nghiệm với 3 lần lặp lại, nuôi trong hệ thống nước hở gồm các bể kính có thể tích 15lít, mật độ 2con/lít, với 4 loại thức ăn khác nhau:

Lô 1: ấu trùng (Nauplius) của Artemia (mật độ $5-7$ con/ml)

Lô 2: thịt tôm tươi xay nhuyễn

Lô 3: thức ăn tổng hợp VANNA (INVE THAILAND TLD.)

Lô 4: Copepoda thu ngoài tự nhiên (mật độ 5 - 7 con/ml)

Tất cả các lô cá được chăm sóc như nhau, hàng ngày cá được cho ăn 2 lần vào 8 giờ sáng và 14 giờ chiều, các bể nuôi được xi phông và thay $30-50 \%$ nước.

Các yếu tố môi trường như nhiệt độ, $\mathrm{pH}$, Oxy hòa tan được theo dõi hàng ngày, $\mathrm{NH}_{3} / \mathrm{NH}_{4}{ }^{+}, \mathrm{NO}_{2}^{-}$được theo dõi hàng tuần và duy trì ổn định trong suốt quá trình thí nghiệm.

Định kỳ cân, đo cá 10 ngày/lần, xác định tỷ lệ sống, tăng trưởng chiều dài $(\mathrm{L}, \mathrm{mm})$ và khối lượng $(\mathrm{W}, \mathrm{g})$ của các lô cá thí nghiệm.

Tốc độ sinh trưởng đặc trưng về chiều dài toàn thân $\left(\mathrm{SGR}_{\mathrm{L}}\right)$ cá được xác định theo công thức:

$$
\mathrm{SGR}_{\mathrm{L}}=\frac{L n L_{2}-L n L_{1}}{t_{2}-t_{1}} \times 100
$$

Trong đó: $\mathrm{SGR}_{\mathrm{L}}$ : tốc độ sinh trưởng đặc trưng về chiều dài toàn thân (\% ngày).

$\mathrm{L}_{1}$ : chiều dài cá ở thời điểm $\mathrm{t}_{1}(\mathrm{~mm})$. $\mathrm{L}_{2}$ : chiều dài cá ở thời điểm $\mathrm{t}_{2}(\mathrm{~mm})$.

Số liệu thu được xử lý trên phần mềm MS Excel và SPSS 17.0 for Window. Sử dụng phân tích phương sai một yếu tố (ANOVA -single factor) để đánh giá ảnh hưởng của các loại thức ăn lên sinh trưởng và tỷ lệ sống của cá khoang cổ nemo. 


\section{KẾT QUẢ VÀ THẢO LUẬN}

\section{Một số yếu tố môi trường trong các bể thí nghiệm}

Một số yếu tố môi trường trong các bể thí nghiệm được trình bày trong bảng 1 .

Bảng 1: Một số yếu tố môi trường trong hệ thống bể nuôi

\begin{tabular}{|c|c|c|c|c|c|}
\hline $\begin{array}{c}\text { Độ muối } \\
(\%)\end{array}$ & $\begin{array}{c}\text { Nhiệt độ } \\
\left({ }^{\mathbf{0}} \mathbf{C}\right)\end{array}$ & $\mathbf{p H}$ & $\begin{array}{c}\mathbf{N H}_{\mathbf{3}}{ }^{+} \\
(\mathbf{m g / l})\end{array}$ & $\begin{array}{c}\mathbf{N O}_{2}{ }^{-} \\
(\mathbf{m g} / \mathbf{l})\end{array}$ & $\begin{array}{c}\text { Oxy hoà tan } \\
(\mathbf{D O})(\mathbf{m g} / \mathbf{l})\end{array}$ \\
\hline$\frac{30-35}{32,6 \pm 1,59}$ & $\frac{24,5-27,5}{26,1 \pm 0,84}$ & $7,7-8,3$ & $0-0,01$ & $\frac{0-0,1}{0,05 \pm 0,33}$ & $\frac{5-6}{5,5 \pm 0,43}$ \\
\hline
\end{tabular}

Trong quá trình thí nghiệm, hàm lượng Oxy hòa tan tương đối ổn định (bảng 1). Độ muối, nhiệt độ và pH trong bể nuôi biến động do lượng nước được bổ sung hàng ngày sau khi xi phông, đặc biệt hàm lượng nitrite tăng dần (từ $0 \mathrm{mg} / \mathrm{l}$ đến $0,1 \mathrm{mg} / \mathrm{l}$ ) do quá trình trao đổi chất của cá tăng cùng với sự tăng trưởng của cá trong quá trình nuôi. Tuy nhiên, các yếu tố môi trường trong bể nuôi đều nằm trong giới hạn cho phép đối với cá Khoang cổ (Hà Lê Thị Lộc, 2005).

\section{2. Ảnh hưởng của các loại thức ăn khác nhau đến tốc độ tăng trưởng cá khoang cổ nemo}

Kết quả cho thấy cá khoang cổ nemo 60 ngày tuổi có chiều dài và khối lượng trung bình đạt cao nhất ở lô cho ăn Copepoda ( $21,8 \mathrm{~mm}$ và $0,204 \mathrm{~g})$, nhưng không khác nhau đáng kể $(\mathrm{P}>0,05)$ so với lô cá ăn thức ăn tổng hợp $(21,5 \mathrm{~mm}$ và $0,19 \mathrm{~g})$. Trong khi đó, chiều dài và khối lượng trung bình của lô cá ăn Artemia $(20,3 \mathrm{~mm} ; 0,16 \mathrm{~g})$, đặc biệt là lô ăn thịt tôm $(17,2 \mathrm{~mm} ; 0,102 \mathrm{~g})$ thấp hơn đáng kể $(\mathrm{P}<0,05)$ so với cá ăn Copepoda và thức ăn tổng hợp (bảng 2).

Tốc độ sinh trưởng đặc trưng về chiều dài và tỷ lệ sống của cá Khoang cổ nemo thí nghiệm được thể hiện ở bảng 3 .

Tốc độ sinh trưởng đặc trưng trung bình ngày của lô cá ăn Copepoda (1\%/ngày) cao nhất trong 4 lô thí nghiệm và không sai khác về mặt thống kê $(\mathrm{P}>0.05)$ so với cá ăn thức ăn tổng hợp $(0,98 \% / n g a ̀ y)$ nhưng cao hơn đáng kể $(\mathrm{P}<0.05)$ so với cá ăn Artemia ( $0,87 \% / n g a ̀ y)$, đặc biệt là cá ăn thịt tôm tươi ( $0,53 \% /$ ngày). 
Bảng 2: Tăng trưởng chiều dài $(\mathrm{L}, \mathrm{mm})$ và khối lượng $(\mathrm{W}, \mathrm{g})$ của cá Khoang cổ nemo với các loại thức ăn khác nhau

\begin{tabular}{|c|c|c|c|c|c|}
\hline \multirow{2}{*}{$\begin{array}{l}\text { Chỉ } \\
\text { tiêu }\end{array}$} & \multirow{2}{*}{$\begin{array}{c}\text { Tuổi } \\
\text { (ngày) }\end{array}$} & \multicolumn{4}{|c|}{ Loại thức ăn } \\
\hline & & Artemia & Tôm & Tổng hợp & Copepoda \\
\hline \multirow{6}{*}{$\begin{array}{c}\mathrm{L} \\
(\mathrm{mm})\end{array}$} & 15 & $13,2 \pm 0,2^{\mathrm{a}}$ & $13,2 \pm 0,2^{\mathrm{a}}$ & $13,2 \pm 0,2^{\mathrm{a}}$ & $13,2 \pm 0,2^{\mathrm{a}}$ \\
\hline & 25 & $16,3 \pm 0,37^{\mathrm{a}}$ & $14,1 \pm 0,19^{b}$ & $15,3 \pm 0,3^{\mathrm{c}}$ & $16,2 \pm 0,28^{a}$ \\
\hline & 35 & $17,7 \pm 0,34^{\mathrm{a}}$ & $15,0 \pm 0,16^{\mathrm{b}}$ & $16,5 \pm 0,35^{\mathrm{c}}$ & $17,9 \pm 0,35^{\mathrm{a}}$ \\
\hline & 45 & $18,3 \pm 0,25^{\mathrm{a}}$ & $15,8 \pm 0,27^{b}$ & $18,4 \pm 0,36^{\mathrm{a}}$ & $18,7 \pm 0,34^{\mathrm{a}}$ \\
\hline & 55 & $19,5 \pm 0,32^{\mathrm{a}}$ & $16,5 \pm 0,31^{\mathrm{b}}$ & $20,3 \pm 0,35^{\mathrm{ac}}$ & $20,6 \pm 0,32^{c}$ \\
\hline & 60 & $20,3 \pm 0,23^{\mathrm{a}}$ & $17,2 \pm 0,22^{b}$ & $21,5 \pm 0,32^{\mathrm{c}}$ & $21,8 \pm 0,33^{\mathrm{c}}$ \\
\hline \multirow{6}{*}{ W $(g)$} & 15 & $0,04 \pm 0,0017^{\mathrm{a}}$ & $0,04 \pm 0,0017^{\mathrm{a}}$ & $0,04 \pm 0,0017^{\mathrm{a}}$ & $0,04 \pm 0,0017^{\mathrm{a}}$ \\
\hline & 25 & $0,071 \pm 0,0045^{\mathrm{a}}$ & $0,043 \pm 0,0023^{b}$ & $0,053 \pm 0,003^{\mathrm{c}}$ & $0,075 \pm 0,0039^{\mathrm{a}}$ \\
\hline & 35 & $0,096 \pm 0,0053^{\mathrm{a}}$ & $0,052 \pm 0,0024^{\mathrm{b}}$ & $0,08 \pm 0,0056^{\mathrm{c}}$ & $0,1 \pm 0,0057^{\mathrm{a}}$ \\
\hline & 45 & $0,1 \pm 0,0052^{\mathrm{a}}$ & $0,062 \pm 0,0037^{b}$ & $0,1 \pm 0,0073^{\mathrm{a}}$ & $0,111 \pm 0,0075^{\mathrm{a}}$ \\
\hline & 55 & $0,14 \pm 0,01^{\mathrm{a}}$ & $0,09 \pm 0,0033^{b}$ & $0,142 \pm 0,0084^{\mathrm{a}}$ & $0,167 \pm 0,012^{\mathrm{c}}$ \\
\hline & 60 & $0,16 \pm 0,0086^{\mathrm{a}}$ & $0,102 \pm 0,0054^{\mathrm{b}}$ & $0,19 \pm 0,0066^{c}$ & $0,204 \pm 0,0075^{\mathrm{c}}$ \\
\hline
\end{tabular}

Số liệu trình bày trên bảng là giá trị trung bình \pm độ lệch chuẩn. Số liệu cùng hàng có các chũ cái khác nhau thể hiện sai khác có ýnghĩa thống kê $(p<0,05)$

Bảng 3: Tốc độ sinh trưởng đặc trưng về chiều dài và tỷ lệ sống của cá Khoang cổ nemo với các loại thức ăn khác nhau.

\begin{tabular}{|c|c|c|c|c|c|}
\hline \multirow{2}{*}{ Chỉ tiêu } & Tuổi & \multicolumn{4}{|c|}{ Loại thức ăn } \\
\cline { 3 - 6 } & (ngày) & Artemia & Tôm & Tổng họ̣p $^{\text {Copepoda }}$ \\
\hline \multirow{4}{*}{$\begin{array}{c}\text { SGR }_{\mathrm{L}} \\
(\% / n g a ̀ y)\end{array}$} & 25 & $2,11 \pm 0,206^{\mathrm{a}}$ & $0,69 \pm 0,212^{\mathrm{b}}$ & $1,44 \pm 0,296^{\mathrm{c}}$ & $2,06 \pm 0,251^{\mathrm{a}}$ \\
\cline { 2 - 6 } & 35 & $0,83 \pm 0,245^{\mathrm{a}}$ & $0,60 \pm 0,199^{\mathrm{b}}$ & $0,77 \pm 0,278^{\mathrm{b}}$ & $0,95 \pm 0,248^{\mathrm{a}}$ \\
\cline { 2 - 6 } & 55 & $0,33 \pm 0,209^{\mathrm{a}}$ & $0,51 \pm 0,187^{\mathrm{a}}$ & $1,09 \pm 0,274^{\mathrm{b}}$ & $0,44 \pm 0,26^{\mathrm{a}}$ \\
\cline { 2 - 6 } & 60 & $0,43 \pm 0,137^{\mathrm{a}}$ & $0,43 \pm 0,167^{\mathrm{a}}$ & $0,56 \pm 0,214^{\mathrm{a}}$ & $0,55 \pm 0,179^{\mathrm{a}}$ \\
\cline { 2 - 6 } & $\mathrm{TB}$ & $0,87^{\mathrm{a}}$ & $0,53^{\mathrm{b}}$ & $0,98^{\mathrm{c}}$ & $1,0^{\mathrm{c}}$ \\
\hline \multicolumn{2}{|c|}{ Tỷ lệ sống (\%) } & $88^{\mathrm{a}}$ & $74^{\mathrm{b}}$ & $84^{\mathrm{a}}$ & $80^{\mathrm{a}}$ \\
\hline
\end{tabular}

Số liệu trình bày trên bảng là giá trị trung bình \pm độ lệch chuẩn. 
Trong sản xuất giống cá khoang cổ nemo, ấu trùng Artemia là thức ăn chủ yếu cho cá con từ 3 ngày tuổi. Do vậy, trong 10 ngày đầu thí nghiệm, đối với lô thức ăn tôm và thức ăn tổng hợp, cá chưa quen với tập tính bắt mồi tĩnh cùng với sự khác nhau về kích cỡ, độ nổi và chất lượng của thức ăn, những yếu tố này có thể ảnh hưởng đến khả năng bắt mồi của cá, dẫn đến tốc độ sinh trưởng đặc trưng ngày chậm hơn so với cá ăn ấu trùng của Artemia và Copepoda. Sau thời gian thích nghi dần với loại thức ăn mới, tốc độ sinh trưởng đặc trưng của cá, đặc biệt là ở lô ăn thức ăn tổng hợp không có sự khác biệt so với cá ăn Copepoda. Sau đó, tốc độ sinh trưởng đặc trưng ngày giảm dần theo thời gian thí nghiệm, nói cách khác, cá càng lớn thì tốc độ sinh trưởng đặc trưng ngày của chúng chậm dần.

Nhiều nghiên cứu trước đây đã xác định thành phần dinh dưỡng của Artemia thường thiếu một số axit béo không no cần thiết (HUFA: Highly unsaturated faty acid). Trong khi đó Copepoda có hàm lượng các axit béo không no cần thiết cao hơn Artemia, đặc biệt hai loại quan trọng cho sự phát triển của ấu trùng nhiều loài cá biển là DHA (22:6n-3 docosahexaenoic acid) và EPA (20:5n-3 eicosapentaenoic acid) (Payne và cs. 2000; Bell và cs, 2003; Trương Sĩ Kỳ và cs. 2007). Do vậy, cá ăn Artemia có thể không đáp ứng nhu cầu axit béo không no cần thiết, dẫn đến tăng trưởng chậm hơn so với cá ăn Copepoda (bảng 2 và 3 ).

Thức ăn tổng hợp được sử dụng ngày càng phổ biến trong sản xuất giống nuôi thủy sản bởi chúng có ưu điểm là sẵn có trên thị trường và thường được bổ sung các thành phần vi lượng cần thiết cho cá nuôi. Kết quả nghiên cứu mới đây ở cá khoang cổ đỏ cho thấy: cá ăn thức ăn tổng hợp, sau 60 ngày tuổi đạt tăng trưởng cao nhất về chiều dài và khối lượng $(24,4 \mathrm{~mm}$ và $0,284 \mathrm{~g})$ so với các lô cá ăn thức ăn tôm $(23,8 \mathrm{~mm}$ và $0,272 \mathrm{~g})$ và Artemia (24,3 mm và 0,281 g) (Hà Lê Thị Lộc và Bùi Thị Quỳnh Thu, 2009). Trong thí nghiệm này, cá ăn thức ăn tổng hợp có tốc độ tăng trưởng không sai khác đáng kể (P > 0.05) so với cá ăn Copepoda.

\section{Tỷ lệ sống của cá ở các nghiệm thức thức ăn khác nhau}

Kết quả ở bảng 3 cho thấy, tỷ lệ sống của cá khoang cổ nemo khi nuôi ở các nghiệm thức thức ăn khác nhau đạt cao nhất ở nghiệm thức Artemia (88\%), tiếp theo là thức ăn tổng hợp $(84 \%)$ và Copepoda $(80 \%)$, thấp nhất là thức ăn tôm $(74 \%)$.

Qua theo dõi thí nghiệm, cá chết nhiều vào tuần đầu khi bắt đầu chuyển đổi các loại thức ăn khác nhau. Các bể nuôi đều được chăm sóc như nhau, các yếu tố môi trường trong bể nuôi đều được duy trì ổn định trong quá trình thí nghiệm và nằm trong phạm vi giới hạn đối với cá nuôi (bảng 1). Vì vậy, sự khác nhau về tỷ lệ sống ở các lô thí nghiệm là do chế độ thức ăn khác nhau. 
Kết quả nghiên cứu mới đây ở cá khoang cổ đỏ cho thấy tỷ lệ sống của cá nuôi bằng các thức ăn ấu trùng Artemia, thịt tôm, và thức ăn tổng hợp đều cao hơn 90\% (Hà Lê Thị Lộc và Bùi Thị Quỳnh Thu, 2009). Trong nghiên cứu này, cá Khoang cổ nemo sử dụng các loại thức ăn tương ứng như trên có tỷ lệ sống dao động từ $74-88 \%$. Sự khác nhau về tỷ lệ sống của cá Khoang cổ nemo trong nghiên cứu này so với cá Khoang cổ đỏ có thể do nhiều yếu tố bên trong và bên ngoài, đặc biệt sự khác nhau về kích thước (cá khoang cổ nemo thường nhỏ hơn cá khoang cổ đỏ với cùng độ tuổi), đặc điểm sinh lý và khả năng thích nghi của loài cũng là một yếu tố quan trọng liên quan đến tăng trưởng và tỷ lệ sống của cá.

Kết quả thí nghiệm cho thấy, tương tự như cá Khoang cổ đỏ, có thể sử dụng thức ăn tổng hợp thay thế thức ăn sống (Copepoda, ấu trùng Artemia) ở giai đoạn cá Khoang cổ nemo giống để giảm chi phí trong sản xuất.

\section{KẾT LUẬN}

- Tăng trưởng của cá khoang cổ nemo 60 ngày tuổi ăn Copepoda $(21,8$ mm và 0,204 g) và thức ăn tổng hợp (21,5 mm và $0,19 \mathrm{~g})$ cao hơn đáng kể so với cá ăn Artemia (20,3 mm; $0,16 \mathrm{~g})$ và ăn thịt tôm tươi xay nhuyễn $(17,2 \mathrm{~mm} ; 0,102 \mathrm{~g})$.

- Tốc độ sinh trưởng đặc trưng trung bình ngày của cá Khoang cổ nemo ăn Copepoda (1\%/ngày) và thức ăn tổng hợp $(0,98 \% / n g a ̀ y)$ cao hơn đáng kể so với cá ăn Artemia $(0,87 \% /$ ngày) và thịt tôm $(0,53 \% /$ ngày $)$.

- Tỷ lệ sống của cá khoang cổ nemo 60 ngày tuổi dao động từ 74 - 88\%, đạt cao nhất ở nghiệm thức ấu trùng Artemia (88\%), tiếp theo là thức ăn tổng hợp $(84 \%)$ và Copepoda (80\%), đạt thấp nhất ở nghiệm thức thịt tôm tươi (74\%).

\section{TÀI LIỆU THAM KHẢO}

1. Hà Lê Thị Lộc, 2004. Một số đặc điểm dinh dưỡng của cá Khoang cổ đỏ Amphiprion frenatus Brevoort, 1856 vùng biển Nha Trang Khánh Hoà. Tuyển tập nghiên cứu biển. NXB Khoa học kỹ thuật. Tập XIV. Trang 163-168.

2. Hà Lê Thị Lộc, 2005. Nghiên cứu cơ sở sinh thái, sinh học phục vụ cho sinh sản nhân tạo cá Khoang cổ (Amphiprion sp) vùng biển Khánh Hoà. Luận án tiến sĩ sinh học Nha Trang. 174 trang. 
3. Hà Lê Thị Lộc, Nguyễn Thị Thanh Thủy, 2009. Ảnh hưởng của thức ăn đến tỷ lệ sống và tăng trưởng của cá Khoang cổ đỏ (Amphiprion frenatus brevoort 1856) giống. Tạp chí Khoa học và Công nghệ biển 9(2): 81- 89.

4. Hà Lê Thị Lộc, Bùi Thị Quỳnh Thu, 2009. Ảnh hưởng của thức ăn đến tăng trưởng, tỷ lệ sống và màu sắc của cá Khoang cổ đỏ Amphiprion frenatus Brevoort 1856. Tuyển tập Hội nghị khoa học toàn quốc về sinh vật biển và phát triển bền vững. Tiểu ban Công nghệ sinh học biển và Môi trường. NXB Khoa học tự nhiên và Công nghệ: 443 -450.

5. Bell J.G., L.A. McEvoy, A. Estevez, R.J. Shields and J.R. Sargent, 2003. Optimising lipid nutrition in first-feeding flatfish larvae. 3rd Fish and Shellfish Larviculture Symposium. Aquaculture 227: 211-220.

6. Payne, M.F. and R.J. Rippingale, 2000. Rearing West Australian seahorse, Hippocampus subelongatus, juveniles on copepod nauplii and enriched Artemia. Aquaculture, 353-361.

\title{
EFFECT OF FOODS ON THE SURVIVAL RATE AND GROWTH SPEED OF NEMO FISH (AMPHIPRION OCELLARIS CUVIER, 1830)
}

\author{
NGUYEN THI THANH THUY, HA LE THI LOC
}

\begin{abstract}
Summary: Nemo fish (Amphiprion ocellaris) were cultured in open system including 15-liter tanks, with density of 2 individuals/liter and fed on 4 different diets separately: diet 1: Nauplius of Artemia (density of 5-7 individuals $/ \mathrm{ml}$ ); diet 2: shrimp flesh; diet 3: commercial diet (VANNA); diet 4: Copepod (density of $5-7$ individuals $/ \mathrm{ml}$ ). Survival and health of the fish were observed daily. Every 10 days, total length $(\mathrm{L}, \mathrm{mm})$, weight $(W, g)$ and specific growth rate in length ( $\left.S G R_{L} \% / d a y\right)$ of the fish were estimated. The result showed that the length and weight of 60 days-old nemo fish fed on Copepod (21.8mm and $0.204 \mathrm{~g}$ ) and commercial diet $(21.5 \mathrm{~mm}$ and $0.19 \mathrm{~g})$ were significantly higher than those of the fish fed on Artemia (20.3mm; 0.16g) and shrimp flesh (17.2mm; $0.102 \mathrm{~g})$. The average specific growth rate of the fish fed on Copepod (1\%/day) and the commercial diet (0.98\%/day) were significantly higher than those of the fish fed on Artemia (0.87\%/day) and shrimp flesh (0.53\%/day). The survival rate of the fish ranged from 74-88\%, with the highest of the fish fed on Artemia (88\%), following the fish fed on commercial diet (84\%) and Copepod (80\%), the lowest of the fish fed on shrimp flesh (74\%).
\end{abstract}

Ngày nhận bài: 20 - 02 - 2010

Ngưòi nhận xét: PGS. TS. Nguyễn Hũu Phụng 